\title{
Professores dos Três Primeiros Anos do Ensino Fundamental da Rede Municipal de São Paulo e suas Relações com o Currículo Prescrito e Apresentado no Ensino de Matemática
}

\author{
Teachers of the First Three Years of Elementary School in the São Paulo \\ Municipal Schools and their Relation with the Curriculum Prescribed and \\ Presented for Mathematics Teaching
}

Janaina Pinheiro Vece*

Edda Curi*

\begin{abstract}
Resumo
Este artigo tem como finalidade investigar, com base nos estudos de Sacristán, a dimensão prescrita e a apresentada do currículo de Matemática, em um recorte de uma pesquisa inserida num projeto alocado no Programa de Melhoria do Ensino Público da FAPESP. Usa como metodologia de pesquisa o grupo focal, com objetivo de identificar as percepções dos professores de $1^{\circ}$ ao $3^{\circ}$ ano do Ensino Fundamental a respeito do currículo de Matemática da Secretaria Municipal de São Paulo. A pesquisa mostra que os professores possuem noções do currículo prescrito, mas não o conhecem por completo e afirmam utilizar o currículo apresentado, adaptando-o e introduzindo suas próprias estratégias de ensino.
\end{abstract}

Palavras-chave: Currículo Prescrito. Currículo Apresentado. Matemática. Professores dos Anos Iniciais do Ensino Fundamental.

\begin{abstract}
This article aims to investigate, based on studies of Sacristán, the math curriculum prescribed and presented dimension in a cutout of a research inserted in a project allocated in a FAPESP Public Education improvement program. It uses the focal group as research methodology, aiming to identify the perceptions of teachers from the 1st to 3rd years of Elementary School related to the Mathematics curriculum of São Paulo Municipal Secertariat. Research shows that teachers have notions of prescribed curriculum, but do not know it completely. They also claim to use the curriculum presented by adapting and introducing their own teaching strategies.
\end{abstract}

\footnotetext{
* Mestra no Ensino de Ciências e Matemática pela Universidade Cruzeiro do Sul (UNICSUL). Professora líder da disciplina Metodologia e Prática do Ensino da Matemática e Ciências da Universidade Paulista (UNIP), São Paulo, SP, Brasil. Endereço para correspondência: Rua Dona Gertrudes Jordão, 251, Quadra 4 - Casa 10, CEP: 053747-020, São Paulo, SP, Brasil.E-mail: jpvece@gmail.com.

** Doutora em Educação Matemática pela Universidade Cruzeiro do Sul (UNICSUL). Coordenadora do Programa de Pós-Graduação do Ensino de Ciências e Matemática da Universidade Cruzeiro do Sul (UNICSUL), São Paulo, SP, Brasil. Endereço para correspondência: Rua Galvão Bueno, 868, Liberdade, CEP: 01506-000, São Paulo, SP, Brasil.E-mail: edda.curi@cruzeirodosul.edu.br.
} 
Keywords: Prescribe Curriculum. Presented Curriculum. Mathematic. Teachers of the Beginning Years of Elementary Education.

\section{Introdução}

Ao longo da história, o currículo escolar assumiu um posicionamento nuclear e dinâmico. O currículo não é um documento fechado e burocrático; pelo contrário, é orgânico e envolve desde a sua idealização até a sua projeção na sala de aula. Sendo assim, todo o processo de ensino e aprendizagem que acontece na escola faz parte do currículo: documentos oficiais, material didático, formas como o professor usa esse material, conhecimentos construídos pelos alunos e avaliação do processo de aprendizagem. Todos esses elementos constituem a dinâmica do currículo escolar.

No Brasil, em cumprimento à Constituição Federal (BRASIL, 1988) e à LDBEN 9.394/96 (BRASIL, 1996), foram elaborados, pelo MEC e pelo Conselho Nacional da Educação, documentos curriculares para as diferentes etapas da Educação Básica; entre eles, os Parâmetros Curriculares Nacionais para o Ensino Fundamental (BRASIL, 1997). Passados mais de quinze anos da publicação desse documento, estados e municípios brasileiros têm se mobilizado em prol da organização de documentos curriculares para orientar as redes de ensino.

Nesse contexto se situa a Secretaria Municipal de São Paulo, que, no ano de 2007, publicou as Orientações Curriculares e Proposição de Expectativas de Aprendizagem para o Ensino Fundamental ${ }^{1}$. O programa de orientação curricular teve por objetivos: contribuir para a reflexão e a discussão sobre o que os estudantes precisam aprender, relativamente a cada uma das áreas de conhecimento; e subsidiar as escolas para o processo de seleção e organização dos conteúdos ao longo do Ensino Fundamental. Para operacionalizar esse documento, a Secretaria Municipal de Educação de São Paulo - SME-SP publicou os Cadernos de Apoio e Aprendizagem de Língua Portuguesa e Matemática ${ }^{2}$, destinados aos alunos de $1^{\circ}$ ao $9^{\circ}$ ano.

O fato de o currículo ter se revertido em um processo de discussão nas escolas e a iniciativa da SME-SP de oferecer aos professores um material próprio e exclusivo, em

\footnotetext{
1 O Documento está disponível para download no link: <http://portalsme.prefeitura.sp.gov.br/Document os/BibliPed/EnsFundMedio/CicloI/OrientaCurriculares_ExpectativasAprendizagem_EnsFnd_cicloI.pdf $>$.

2 Esses Cadernos estão disponíveis para download no link: <http://portalsme.prefeitura.sp.gov.br/Projetos/ BibliPed/Anonimo/Publicacao2013/CadernosdeApoioeAprendizagemMatem.aspx?MenuID=44\&MenuIDAberto $=42>$.
} 
especial sobre o ensino de Matemática, tornaram-se um interessante foco de investigação, a fim de compreender a concepção de currículo e seus desdobramentos.

Nesse sentido, foi realizado o projeto de pesquisa com apoio da Fundação de Amparo à Pesquisa do Estado de São Paulo (FAPESP), denominado "Avaliação de Professores do Ensino Fundamental da Secretaria Municipal de Educação de São Paulo, em relação a documentos e materiais de apoio à organização curricular na área de Educação Matemática". Desenvolvido em parceria com a Universidade Cruzeiro do Sul (UNICSUL), com a Pontifícia Universidade Católica de São Paulo (PUC/SP) e com as escolas da rede pública municipal de São Paulo, o projeto buscou analisar os impactos de documentos curriculares na prática e no desenvolvimento profissional de 33 professores do Ensino Fundamental.

Neste artigo, apresentamos um recorte dessa pesquisa, que consiste em apurar " $O$ que revelam os professores que atuam nos três primeiros anos do ensino fundamental da SME-SP sobre o currículo prescrito e o apresentado, no que se refere ao ensino de Matemática?".

\section{Fundamentação teórica}

A pesquisa fundamenta-se nos estudos de Sacristán $(1998,2000)$ sobre currículos, este afirma que o currículo organiza a escola, propõe caminho e orientações para a prática (SACRISTÁN, 2000, p. 15). O autor destaca ainda a importância dos objetivos da escola e do contexto, dos conteúdos e das ações práticas em um currículo, não de forma burocrática e mecânica, mas envolvendo o contexto da escola e as consequências para a prática pedagógica e a formação do educando. Sobre as funções do currículo, afirma que

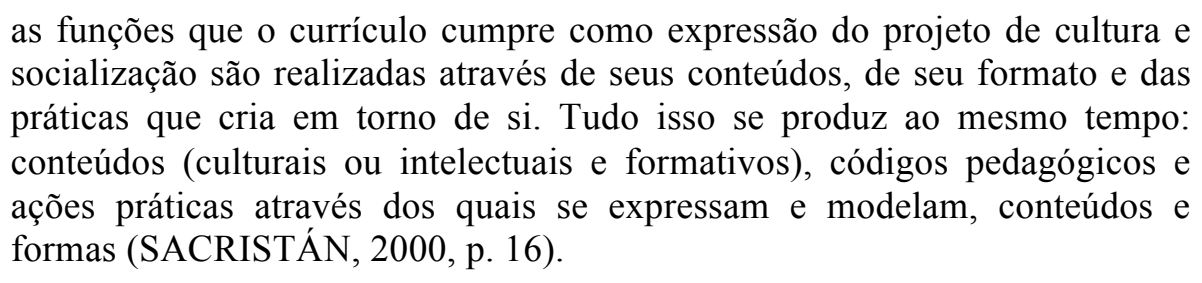

Nesse mesmo estudo, o autor chama a atenção sobre as funções integradas, socializadoras e culturais que se atribuem à escola e destaca que elas se refletem nos objetivos que orientam o currículo escolar. Ele afirma que todas as finalidades - de socialização, de formação, de segregação ou de integração social etc. - que se atribuem e são destinadas, implícita ou explicitamente, à instituição escolar acabam necessariamente tendo um reflexo nos objetivos que orientam todo o currículo, na seleção de seus componentes, e desembocam numa divisão especialmente ponderada entre diferentes parcelas curriculares e nas próprias 
atividades metodológicas. Por isso, o interesse pelos problemas relacionados com o currículo não é senão consequência da consciência de que por meio dele se realizam basicamente as funções da escola como instituição (SACRISTÁN, 2000, p. 17).

O autor salienta também que um currículo educacional não existe fora do contexto histórico social ao qual ele se destina, pois a política e os mecanismos educacionais intervêm diretamente no currículo escolar e na concepção de educação que o subsidia.

Esse mesmo autor discorre ainda sobre o currículo como uma prática que se realiza em diferentes dimensões - o currículo prescrito; o currículo apresentado; o currículo moldado pelos professores; o currículo em ação; o currículo avaliado -, com a participação de diversos atores que serão descritos a seguir.

Para Sacristán (2000), o currículo prescrito indica diretrizes para a educação e a escola, objetivos e processos de ensino e aprendizagem de uma dada área de conhecimento, em função do que se espera das aprendizagens dos alunos. É um documento de referência para as outras instâncias curriculares. Apresenta fundamentos teóricos, orientações didáticas e metodológicas e critérios de avaliação. Pode ter outras denominações, como "currículo formal" ou "oficial".

O currículo apresentado, segundo o autor, é, no geral, formulado por autores de livros didáticos e/ou de outros materiais didáticos instrucionais. Esses materiais operacionalizam as orientações curriculares expressas nos currículos prescritos.

O currículo moldado pelos professores em seu planejamento anual, segundo Sacristán (2000), é elaborado a partir do currículo prescrito e do apresentado, adequando-os às necessidades dos estudantes. Procura ajustá-los e articulá-los aos planos de curso das diferentes disciplinas, de modo a convergir para as metas mais amplas da escola, com base no diagnóstico da comunidade onde se insere.

O currículo em ação é a concretização do currículo em sala de aula, em que as atividades são ajustadas em função da interação entre professores, alunos e o conhecimento. Nessa instância, o que foi planejado inicialmente adequa-se aos estudantes, de acordo com suas necessidades.

O currículo avaliado refere-se ao momento em que o professor procura identificar os avanços e as dificuldades de seus alunos, ao longo do processo, por meio de uma avaliação. Nessa instância também se concretiza por meio de avaliações externas.

A articulação e a coerência entre essas diferentes instâncias de desenvolvimento curricular são fundamentais para o processo de ensino e aprendizagem. No entanto, Curi 
(2013) destaca que o currículo organizado e desenvolvido intencionalmente pelo professor convive com o que autores denominam de "currículo oculto", compreendendo situações de ensino não planejadas, decorrentes das relações que se estabelecem na escola e, principalmente, de crenças e concepções dos profissionais da educação.

Nesse sentido, entendemos que é de fundamental importância que os docentes conheçam e reflitam sobre o currículo prescrito e o apresentado, para que decidam de forma mais consciente sobre os objetivos de aprendizagem e a organização de atividades para a sala de aula coerentes com eles. Além disso, observamos, em nossos estudos, que, apesar do avanço das pesquisas, pouco se sabe sobre o currículo efetivamente praticado em sala de aula pelo professor, sobre as interpretações que ele faz das diferentes instâncias curriculares, bem como sobre as adaptações e as intervenções que realiza.

\section{Metodologia de pesquisa}

O trabalho com grupo focal tem merecido destaque em pesquisas na área da educação. Para Caplan (1990), o principal objetivo do grupo focal é identificar percepções, atitudes e ideias dos participantes a respeito de um determinado assunto, produto ou atividade, o que justifica a escolha dessa metodologia para nossa pesquisa, pois, ao invés de inferir e/ou generalizar, buscamos compreender a perspectiva dos participantes sobre um determinado assunto.

Como já afirmamos, neste texto apresentamos o recorte do projeto de pesquisa “Avaliação de Professores do Ensino Fundamental da Secretaria Municipal de Educação de São Paulo, em relação a documentos e materiais de apoio à organização curricular na área de Educação Matemática", que se desenvolveu de agosto de 2011 a maio de 2013. O grupo foi composto por professores de $1^{\circ}$ ao $9^{\circ}$ anos do Ensino Fundamental da SME-SP que estivessem dispostos a participar da pesquisa e que declarassem a utilização do Caderno de Apoio e Aprendizagem de Matemática (CAAM) (SÃO PAULO, 2010).

Nesse sentido, Caplan (1990) sugere que a constituição do grupo seja voluntária, uma vez que o grupo focal se desenvolve por meio de uma perspectiva dialética, em que os envolvidos possuem interesses e objetivos comuns, sendo extremamente importante a participação de todos, porém sem coação.

No ano de 2011 foram realizadas seis reuniões com os participantes da pesquisa, com duração de quatro horas cada, com a finalidade de definir as responsabilidades de cada um e 
fazer alguns estudos pertinentes ao projeto. Dessa forma, o grupo focal foi organizado de acordo com a vivência prática dos professores e o uso do CAAM, e, ao longo do processo, foi dividido em subgrupos, conforme o ano de atuação dos professores nas escolas. Cada subgrupo foi acompanhado por um pesquisador colaborador, orientado pelas coordenadoras do projeto. Os subgrupos que correspondem ao público de pesquisa deste artigo reuniram professores de $1^{\circ}, 2^{\circ}$ e $3^{\circ}$ anos do Ensino Fundamental.

Para definir o perfil do grupo, os participantes responderam a um questionário com questões básicas acerca de idade, sexo, formação e tempo de exercício no magistério. Dessa forma, para compreender o grupo focal aqui analisado, é importante ressaltar algumas de suas características. O grupo, composto por 12 participantes, sendo 10 do sexo feminino e apenas 1 do sexo masculino, apresentou a idade média de 40 anos. O tempo médio de exercício no magistério da Prefeitura de São Paulo declarado pelos professores no questionário foi de oito anos, o que poderia indicar um grupo de jovens professores. Porém, o grupo era composto de professores em início de carreira e de aposentados de outras redes, que atuavam no sistema municipal há pouco tempo. A maioria declarou formação inicial no Magistério e Licenciatura Plena em Pedagogia, sendo duas professoras com Licenciatura Plena em Matemática e dois professores com Licenciatura Plena em Letras.

No ano de 2012, foram planejadas duas reuniões mensais, em que as coordenadoras, os professores e os pesquisadores colaboradores planejaram e discutiram o trabalho realizado nas salas de aula com o uso dos CAAM. O ano de 2013 foi dedicado à sistematização dos relatórios e das atividades para envio ao órgão de fomento da pesquisa.

As discussões no grupo focal aconteceram numa atmosfera agradável e informal, com intuito de deixar os professores à vontade para expor ideias, sentimentos, necessidades e opiniões. Para Gaskel (2000), no grupo focal, a energia gerada pela união dos envolvidos produz mais informações e com maior riqueza de detalhes do que o somatório das respostas individuais.

Ao longo dos inúmeros encontros, recorrendo à metodologia do grupo focal, foram utilizados alguns instrumentos de pesquisa que possibilitaram identificar as impressões e as revelações dos professores sobre o currículo de Matemática. Para este artigo, os instrumentos utilizados para análise se constituíram em questionários, relatórios desenvolvidos pelos participantes e diários de bordo dos pesquisadores colaboradores, com a descrição e a reflexão acerca dos encontros do grupo focal. Adiante apresentaremos a sistematização dos dados colhidos a partir de uma análise estritamente qualitativa. 


\subsection{Análise dos dados}

Considerando as dimensões curriculares propostas por Sacristán (prescrita, apresentada, moldada, praticada e avaliada), focalizamos neste artigo apenas as instâncias prescrita e apresentada. É importante destacar que, na pesquisa, o documento Orientações Curriculares e Proposição de Expectativas de Aprendizagem se insere na dimensão de currículo prescrito e o CAAM, na instância de currículo apresentado. Para tanto, é de suma relevância compreender minimamente a organização e os principais aspectos de cada um deles.

O documento Orientações Curriculares e Proposição de Expectativas de Aprendizagem (SÃO PAULO, 2007, p. 10) orienta a organização curricular da rede municipal de ensino da Prefeitura Municipal de São Paulo a partir de expectativas de aprendizagem por área de conhecimento, com o objetivo de:

[...] contribuir para a reflexão e discussão sobre o que os estudantes precisam aprender, relativamente a cada área de conhecimento, construindo um projeto curricular que atenda às finalidades da formação para a cidadania, subsidiando as escolas na seleção e organização de conteúdos mais relevantes a serem trabalhados ao longo dos nove anos do Ensino Fundamental, que precisam ser garantidos a todos os estudantes.

Além de definir e suscitar discussões sobre o que se espera que os estudantes aprendam no Ensino Fundamental, o documento propõe a mobilização do professorado da rede em torno da proposta de um currículo unificado, mas que respeite as particularidades reais de cada escola, tendo em vista a melhoria da qualidade do ensino.

$\mathrm{Na}$ elaboração de seu projeto pedagógico, cada escola parte da consideração da realidade, da situação em que a escola se encontra, para confrontá-la com o que deseja e necessita construir. Essa "idealização" não significa algo que não possa ser realizado, mas algo que ainda não foi realizado, caracterizando um processo necessariamente dinâmico e contínuo. (SÃO PAULO, 2007, p. 15).

De acordo com o documento oficial da SME-SP, o conceito de currículo é mais amplo do que a simples discussão em torno de conteúdos escolares, no entanto, um dos grandes desafios para os educadores consiste em selecioná-los. Para definir as expectativas de aprendizagem, em especial de Matemática, foram considerados como critérios: a relevância social e cultural; a formação intelectual do aluno e sua potencialidade para a construção de habilidades comuns; a potencialidade de conexões interdisciplinares e de contextualizações; e, por fim, a acessibilidade e a adequação do conteúdo à faixa etária.

Os critérios de seleção das expectativas de aprendizagem evidenciam, conforme Sacristán (2000, p. 36), que “toda essa dinâmica curricular não se produz no vazio, mas 
envolve o campo político e cultural geral, do qual se costumam tomar argumentos, contribuições pretensamente científicas, valores, etc.".

Desse modo, a formulação das expectativas de aprendizagem relativas à Matemática, para os estudantes das escolas, busca o equilíbrio e a indissociabilidade entre dois aspectos: a contribuição para resolver e aplicar problemas da vida cotidiana e o desenvolvimento de capacidades intelectuais, como a estruturação do pensamento e a agilização do raciocínio do aluno.

Sobre o currículo apresentado, o CAAM foi produzido no ano de 2009 pela SME-SP e entregue nas escolas no ano de 2010. Destinado aos alunos dos nove anos do Ensino Fundamental, o material visa contribuir para o trabalho docente e, principalmente, para a melhoria da qualidade do ensino. Sua elaboração envolveu as expectativas de aprendizagem contidas no documento oficial de Orientações Curriculares e Proposição de Expectativas de Aprendizagem e as dificuldades apresentadas pelos alunos na Prova São Paulo ${ }^{3}$ e na Prova da Cidade ${ }^{4}$.

O material de Matemática é composto de 18 cadernos para o atendimento do público do Ensino Fundamental, nove dos quais são destinados aos alunos e nove são manuais para o professor. $\mathrm{Na}$ área de Matemática, os cadernos foram preparados de acordo com os blocos de conteúdos: espaço e forma; grandezas e medidas; números e operações; e tratamento da informação.

Os Cadernos de Apoio e Aprendizagem destinados aos alunos são compostos de oito unidades. Em cada unidade é focalizado um conjunto de expectativas de aprendizagem, de acordo com as orientações curriculares da SME-SP. As unidades possuem uma página de abertura, que introduz a contextualização (situação de uso da Matemática na sala de aula, de acordo com o universo infantil, com a cidade de São Paulo e com temas previstos para Natureza e Sociedade) e o que vai ser estudado, para então, dar início à sequência de atividades compostas por expectativas desenvolvidas, página a página, por meio de problematizações, explorações, investigações, desafios, sistematizações, informações sobre o

\footnotetext{
3 A Prova São Paulo trata-se de uma avaliação externa desenvolvida por uma empresa contratada a partir de licitação pública. Sua participação é obrigatória, pois o seu principal objetivo é diagnosticar as políticas públicas da Secretaria Municipal de Educação.

Informações disponíveis no link: <http://portalsme.prefeitura.sp.gov.br/Projetos/nucleo/AnonimoSistema/Men uTexto.aspx?MenuID=48\&MenuIDAberto $=23>$.

${ }^{4}$ A Prova da Cidade é um prova diagnóstica, cujas propostas de elaboração, aplicação, correção e intervenção estão mais próximas dos profissionais que atuam na escola. Sua participação é por adesão, para tanto, envolve objetivos que se aproximam, em alguns aspectos, de uma avaliação interna.

Informações disponíveis no link: <http://portalsme.prefeitura.sp.gov.br/Projetos/nucleo/AnonimoSistema/Menu Texto.aspx? MenuID=47\&MenuIDAberto=24>.
} 
conteúdo e exercícios. O objetivo das atividades do caderno do aluno é possibilitar o atendimento das expectativas de aprendizagem em Matemática e permitir que os alunos percebam a área de conhecimento em vários contextos, atribuindo-lhe significado.

Além dos cadernos destinados aos alunos, aos professores é oferecido um caderno próprio, com recomendações didáticas que indicam as expectativas de aprendizagem relacionadas às atividades do caderno do aluno; com orientações sobre a gestão da sala de aula, propondo diferentes intervenções para a realização da atividade; e com outros encaminhamentos para o uso do caderno em classe.

Após a breve apresentação dos documentos, vale retomar o nosso foco de pesquisa, que consiste em investigar $O$ que revelam os professores que atuam nos três primeiros anos do Ensino Fundamental da SME-SP sobre o currículo prescrito e o apresentado, no que se refere ao ensino de Matemática?.

\subsubsection{Sobre o currículo prescrito}

Para o levantamento dos dados sobre o currículo prescrito de Matemática, foi proposto um questionário acerca do documento oficial. As questões apresentadas aos professores permitiram identificar como tiveram contato com o documento oficial da SME-SP e como percebem suas orientações. Para tanto, os professores responderam ao seguinte instrumento:

1. Você já leu o documento Orientações Curriculares - Ensino Fundamental I, da SME?
a) $\operatorname{Sim}($ )
b) Não ( )
c) Em parte ( )

Se você assinalou a) ou c), responda às questões seguintes:

2. Como teve contato com essas orientações?

3. Que comentários você destaca sobre esse documento, em termos de contribuições que ele pode ter para o ensino de Matemática na rede municipal?

4. Que relações você estabelece entre as propostas desse documento para a área de Matemática e sua prática em sala de aula? Justifique.

5. As expectativas de aprendizagem que devem ser trabalhadas em cada ano, apresentadas nesse documento, estão enunciadas de forma clara? Exemplifique.

6. Há expectativas de aprendizagem inadequadas ao ano de escolaridade a que se destinam? Quais?

Quadro 1 - Instrumento 1: Questionário sobre o currículo prescrito

Fonte: Instrumento de pesquisa elaborado pelas coordenadoras do grupo focal

Nas respostas expressas pelos professores no questionário, bem como nas falas registradas no diário de bordo a respeito do documento Orientações Curriculares $e$ Proposição de Expectativas de Aprendizagem, foi comum a afirmação de que o primeiro contato havia ocorrido a partir das orientações dadas por coordenadores pedagógicos, nos momentos de elaboração dos planos de ensino anuais, semestrais e bimestrais. Alguns 
revelaram, ainda, que o contato maior se deu na Jornada Especial Integral de Formação JEIF, horário coletivo destinado à formação, à discussão e ao encaminhamentos das necessidades pedagógicas da escola e/ou por intermédio de cursos oferecidos pela Diretoria Regional de Educação.

Sobre as contribuições que o documento oficial trouxe para o ensino de Matemática, os comentários dos grupos de professores foram uniformes, definindo o documento prescrito, como: eixo, diretriz, norteador, referencial e apoio. Os professores compreendem o documento como um material rico, importante para a prática pedagógica, que contribui para a unificação do ensino da rede municipal de São Paulo. Um dos professores revelou que o documento oficial, além de oferecer suporte teórico, traz orientações didáticas e metodológicas e prevê a distribuição de conteúdos para a área em cada ano do ciclo, com indicações sobre o planejamento adequado ao público com que o professor atua.

Acerca das contribuições do currículo prescrito de Matemática, é importante destacar um trecho interessante escrito por uma professora em um de seus relatórios:

Todo material pode ser positivo ou negativo, ter um referencial pode ajudar, desde que o mesmo não seja utilizado sem consciência da dimensão dele, correndo o perigo de servir apenas de reprodução de novos documentos, como o próprio planejamento anual da escola sem que os participantes e executantes desse processo de ensino e aprendizagem tenham a amplitude e representação do que está sendo realizado por ele.

Penso que se fosse analisado criticamente a realidade de cada público, suas falas significativas, e assim a construção de um currículo crítico por parte de cada um seria talvez uma boa saida para algumas dificuldades encontradas, entre elas a falta de interesse.

Por outro lado acredito que a intencionalidade seja positiva, mediante as muitas escolas que perderam ou não conseguiram ter a dimensão do que é necessário ensinar, afinal essas abriram mão desse direito no momento que deixaram de fazê-lo. (Relatório, 22/04/2012, professora do $1^{\circ}$ ano)

Quanto à relação entre a proposta de orientação curricular e a prática em sala de aula, o grupo como um todo, ao responder o questionário, enfatizou que o documento é referência para a organização do trabalho pedagógico; serve como fonte principal para a elaboração do planejamento anual, semanal e diário; e auxilia a organização do processo de ensino e aprendizagem, pois sintetiza o que é importante desenvolver em cada ciclo/ano, a partir das expectativas de aprendizagem. Os docentes revelaram, ainda, que, para propor ajustes no planejamento, retomam o documento para verificar se estão conseguindo alcançar o que foi proposto em termos de expectativa de aprendizagem.

Em sua maioria, os professores indicaram que as expectativas de aprendizagem são 
adequadas ao ano de escolaridade. No entanto, dentre eles, uma professora enfatizou que cabe ao professor adequá-las ao nível de conhecimento dos educandos; quatro apontaram que algumas expectativas de aprendizagem são inadequadas ao $1^{\circ}$ ano, em relação ao ensino de Matemática; e uma sugeriu que as expectativas de aprendizagem poderiam ser mais detalhadas e exemplificou:

Poderiam ser mais ampliadas ou detalhadas, como nas operações, a resolução de problemas com estratégias pessoais, as outras ideias de comparação, proporcionalidade, configuração retangular entre outras poderiam ser acrescidas [...]. Acredito, pelo que eu percebo em sala de aula, que o trabalho com situações nas ideias dos campos multiplicativos apenas com estratégias pessoais e discussões são viáveis e possíveis. (Comentário, 09/06/2012, professora do $1^{\circ}$ ano)

Os questionários respondidos pelo grupo indicam que o objetivo do documento analisado - contribuir para a reflexão e a discussão sobre o currículo prescrito na rede municipal de São Paulo - foi atendido, uma vez que os espaços propícios para a formação continuada foram mencionados pelos professores. No entanto, dos 12 docentes pesquisados, apenas 5 afirmaram ter feito a leitura integral do documento oficial. Os demais revelaram sua leitura apenas parcial.

Tal revelação evidencia a dificuldade apresentada por Sacristán (1999, p. 189), “que propõe um currículo universalizador como componente cultural”, mas que, nas entrelinhas, se resume à apropriação, de fato, do currículo prescrito pela comunidade escolar.

Nesse sentido, podemos dizer que "no currículo se entrecruzam componentes e determinações muito diversas: pedagógicas, políticas, práticas administrativas, produtivas de diversos materiais, de controle sobre o sistema escolar de inovação pedagógica, etc." (SACRISTÁN, 1998, p. 32).

Apesar dos comentários positivos, o fato de a maioria não ter realizado a leitura integral do documento oficial pode evidenciar um conhecimento superficial da dimensão prescrita do currículo. Ao longo do projeto, essa hipótese se confirmou, pois, mesmo avaliando o material de forma positiva, os professores consideraram que ainda faltam muitas informações básicas a respeito de teorias subjacentes às propostas curriculares, o que precisa ser objeto de formação.

Ressaltaram também que, embora o material instigue a reflexão sobre como organizar os diferentes blocos de conteúdo e proporcionar a articulação entre eles no processo de aprendizagem, ainda consideram difícil perceber e destacar algumas conexões que só ficaram visíveis após a discussão no grupo focal. Além disso, os professores elucidaram, em suas falas e nos registros escritos, a necessidade de retomar alguns conhecimentos relativos a conteúdos 
matemáticos, como, por exemplo, as características e o funcionamento do sistema de numeração decimal; os procedimentos usados em técnicas operatórias; e, sobretudo, a geometria, reafirmando a defasagem da formação básica desses professores em relação a alguns conteúdos matemáticos.

Nesse sentido, as contribuições de Shulman (1992) sobre a importância do conhecimento do conteúdo como uma das bases para o exercício da função docente retratam que o domínio dos conceitos, das propriedades e dos procedimentos implica na natureza e nos significados do conteúdo; no seu desenvolvimento histórico; e nas diferentes formas de compreendê-lo e organizá-lo.

Ora, se o conhecimento acerca do conteúdo matemático implica na organização didática do professor, tal conhecimento influencia a proposição de boas situações de aprendizagem.

\subsubsection{Sobre o currículo apresentado}

O instrumento de pesquisa relativo ao CAAM permitiu identificar as impressões dos professores que atuam nos três primeiros anos do Ensino Fundamental, quanto à potencialidade do material no apoio ao trabalho pedagógico durante a sua implementação e seu uso, especificamente, no ano de 2011.

\section{Você teve contato com os Cadernos de Apoio e Aprendizagem - CAA}
a) desde $2010($ )
b) só em 2011 ( )

2. Ao receber esse material, você teve informações sobre qual era a sua finalidade? Que informações?

3. Qual foi sua primeira impressão ao folhear esse material?

4. Os Cadernos de Apoio e Aprendizagem foram elaborados para apoiar o trabalho dos professores na implementação das Orientações Curriculares. No seu caso específico, você considera que eles têm essa potencialidade? Justifique.

5. Em relação ao ano de escolaridade em que você está ensinando em 2011, indique as unidades com as quais você já trabalhou, as que você ainda vai trabalhar e as que não serão trabalhadas, por algum motivo.

\footnotetext{
Quadro 2 - Instrumento 2: Questionário sobre o currículo apresentado Fonte: Instrumento de pesquisa elaborado pelas coordenadoras do grupo focal
}

Quanto ao período de implementação, todos os professores afirmaram conhecer o material desde 2010, ano de seu lançamento, e três deles mencionaram não ter recebido nenhum tipo de orientação de uso. Dentre estes, um professor indicou que, ao receber o CAAM, foi feita a leitura das páginas iniciais, individualmente pelos docentes da escola, sem discussão, no horário coletivo de formação. Oito professores manifestaram ter participado de 
formações em horário de trabalho e em cursos na Diretoria Regional de Educação, que, inclusive, orientaram a utilização do material, pautada nas expectativas de aprendizagem contidas nas Orientações Curriculares e Proposição de Expectativas de Aprendizagem.

Com relação às primeiras impressões causadas pelo CAAM, foi unânime o comentário de que o material consumível oferecido aos alunos causou boa impressão, pela boa qualidade e, principalmente, por disponibilizar vídeos atrativos aos alunos e complementares ao trabalho do professor.

Apresentado como um suporte e/ou uma ferramenta para auxiliar na prática pedagógica diária, uma professora do $2^{\circ}$ ano em um dos encontros manifestou que "o material é bom, mas tudo depende de como ele será utilizado".

Acerca da prática docente e o currículo escolar, Sacristán (1998, p. 32) salienta que o currículo:

[...] é um instrumento que cria toda uma gama de usos, de modo que é elemento imprescindível para compreender o que costumamos chamar de prática pedagógica. [...] Além disso, está estritamente relacionado com o conteúdo da profissionalizalização dos docentes. $\mathrm{O}$ que se entende por bom professor e as funções que se pede que desenvolva, dependem da variação nos conteúdos, finalidades e mecanismos de desenvolvimento curricular.

Todos os professores afirmaram que é possível observar a aproximação das sequências de atividades do CAAM com as expectativas de aprendizagem. No entanto, alguns deles alegaram que é preciso incluir atividades complementares para apoiar as necessidades de aprendizagem dos alunos de suas turmas. Esse aspecto também diz respeito ao estudo do professor, ou seja, à necessidade de preparar e planejar com antecedência o seu trabalho.

De acordo com Shulman (1992), o planejamento do professor concentra-se na combinação entre o conhecimento didático e do conteúdo, para tornar o conteúdo matemático compreensível ao aluno.

Sobre este aspecto, um comentário da professora do $1^{\circ}$ ano, nos chamou a atenção, evidenciando que nem sempre um material é adotado pelo professor de maneira acrítica: a expressão de que "o CAAM não é uma cartilha para ser trabalhada todos os dias e de forma linear" revela que o material não é o único recurso utilizado pelos professores em sala de aula com os alunos. Tal afirmação denota que as expectativas da SME-SP quanto ao uso do CAAM foram atendidas neste grupo de professores, uma vez que o documento reitera que o material deve:

[...] ser complementado com atividades planejadas pelo professor, em função das características de sua turma, fazendo uso de livros didáticos e de outros materiais já publicados pela SME, disponíveis nas escolas, para trabalho com o Ensino Fundamental (Guias de planejamento e orientações didáticas - Ciclo I; Orientações curriculares e proposição de expectativas de aprendizagem do Ciclo I e das áreas de 
conhecimento do Ciclo II; Referenciais de expectativas para o desenvolvimento da competência leitora e escritora - Ciclo II). Para cada ano de escolaridade foram produzidas sequências de atividades para os alunos e orientações didáticas para o professor. A proposta é que estes Cadernos sejam utilizados pelos professores e pelos alunos duas vezes por semana. (SÃO PAULO, 2010, p. 5)

Observamos que os professores avaliam as atividades propostas no CAAM como potencializadoras de práticas, como, por exemplo, o recurso à resolução de problemas e às investigações. No entanto, o material adotado como um meio, e não como um fim, depende das intervenções que cada professor é capaz de fazer em sala de aula.

Apesar de avaliarem positivamente o material, os professores apontaram que ainda faltam informações teóricas subjacentes às propostas curriculares, evidenciando que, embora o material instigue a reflexão sobre como organizar os diferentes blocos de conteúdos matemáticos e como proporcionar a articulação entre eles, no processo de formação dos professores ainda é difícil perceber e destacar conexões com a teoria, que só ficaram visíveis nas discussões no grupo focal.

Dessa forma, ficou evidente a revelação de que, para os professores dos três primeiros anos do ensino fundamental, o CAAM serviu, sem dúvida, como apoio à implementação das Orientações Curriculares e Proposição de Expectativas de Aprendizagem.

Como uma das condições estabelecidas para os professores participarem do grupo focal era o comprometimento com o uso do CAAM, não tivemos professores que declarassem ter deixado de utilizar o material. Na Tabela 1, podemos verificar quais unidades foram desenvolvidas por esses professores com os alunos no ano de 2011, de acordo com os subgrupos de professores do $1^{\circ}, 2^{\circ}$ e $3^{\circ}$ anos:

Tabela 1 - Uso do CAAM no ano de 2011

\begin{tabular}{|c|c|c|c|c|c|c|c|c|c|c|c|c|c|c|c|c|c|}
\hline \multirow{3}{*}{ Subgrupos } & \multirow{3}{*}{$\begin{array}{l}\text { Número de } \\
\text { professores }\end{array}$} & \multicolumn{16}{|c|}{ Unidades dos Cadernos de Apoio e Aprendizagem - Matemática } \\
\hline & & \multicolumn{2}{|c|}{ U1 } & \multicolumn{2}{|c|}{ U2 } & \multicolumn{2}{|c|}{ U3 } & \multicolumn{2}{|c|}{ U4 } & \multicolumn{2}{|c|}{ U5 } & \multicolumn{2}{|c|}{ U6 } & \multicolumn{2}{|c|}{ U7 } & \multicolumn{2}{|c|}{ U8 } \\
\hline & & Sim & Não & Sim & Não & Sim & Não & Sim & Não & Sim & Não & Sim & Não & Sim & Não & Sim & Não \\
\hline $1^{\circ}$ ano & 6 & 5 & 1 & 5 & 1 & 5 & 1 & 5 & 1 & 5 & 1 & 5 & 1 & 2 & 4 & 2 & 4 \\
\hline $2^{\circ}$ ano & 4 & 4 & - & 4 & - & 4 & - & 4 & - & 4 & - & 4 & - & 3 & 1 & 1 & 3 \\
\hline $3^{\circ}$ ano & 2 & 2 & - & 2 & - & 2 & - & 2 & - & 1 & 1 & - & 2 & - & 2 & - & 2 \\
\hline
\end{tabular}

Fonte: Instrumento de pesquisa elaborado pelas coordenadoras do grupo focal

De acordo com as respostas apresentadas pelos professores, no ano de 2011, o trabalho com o CAAM foi realizado parcialmente com os alunos.

A análise da tabela revela alguns dados importantes nos subgrupos: 
- O desenvolvimento integral das unidades 1, 2, 3 e 4, sendo que apenas no grupo de $1^{\circ}$ ano uma professora manifestou não ter utilizado o CAAM com os alunos.

- Da unidade 5 em diante, foi comum entre os subgrupos de professores de $1^{\circ}, 2^{\circ}$ e $3^{\circ}$ anos a redução do trabalho com o CAAM.

Os dados da tabela revelam ainda que, apesar das considerações favoráveis e de reconhecerem a importância do material didático, alguns professores desenvolveram, durante o ano de 2011, poucas unidades do CAAM, declarando elaborar suas próprias sequências de atividades, baseando-se em livros didáticos e em outros materiais.

\section{Considerações finais}

A questão "O que revelam os professores que atuam nos três primeiros anos do Ensino Fundamental da SME-SP sobre o currículo prescrito e o apresentado, no que se refere ao ensino de Matemática?" permite apresentar algumas conclusões acerca da compreensão dos docentes sobre as Orientações Curriculares e Proposição de Expectativas de Aprendizagem e sobre os Cadernos de Apoio e Aprendizagem - Matemática.

Os professores dos três primeiros anos do Ensino Fundamental declararam que o contato com as Orientações Curriculares e Proposição de Expectativas de Aprendizagem aconteceu em momentos de formação em serviço nas escolas e em cursos oferecidos pela Diretoria Regional de Educação, que o documento propiciou ao grupo de professores a reflexão e a discussão sobre o currículo prescrito na rede municipal de São Paulo e contribuiu para o ensino de Matemática, servindo como referência para a organização do trabalho pedagógico individual e coletivo na escola.

Entretanto, apesar dos aspectos positivos quanto à implementação desse documento, a maioria dos professores declarou não ter realizado sua leitura integral e revelou, durante os encontros no grupo focal, conhecimento superficial da dimensão prescrita do currículo.

Sobre o currículo apresentado, os professores dos três primeiros anos do Ensino Fundamental afirmaram que o CAAM serviu como apoio importante para a implementação do documento Orientações Curriculares e Proposição de Expectativas de Aprendizagem, apesar de ter sido lançado três anos após o primeiro documento. Declararam ter conhecimento sobre o material no mesmo ano de seu lançamento, evidenciando que a formação continuada, nas escolas e nos cursos oferecidos pela Diretoria Regional de Educação, tem sido a aposta da rede, ao implementar propostas curriculares. Consideraram o 
material de boa qualidade, mas ressaltaram que sua efetiva contribuição para a aprendizagem depende da forma como o professor o utiliza em sala de aula, ou seja, do planejamento prévio e das atividades complementares.

Apesar das considerações favoráveis e de reconhecerem a importância do material didático, durante o ano de 2011, alguns professores desenvolveram poucas unidades do CAAM e declararam elaborar suas próprias sequências de atividades, baseando-se em livros didáticos e em outros materiais.

As revelações acerca do currículo de Matemática e da sua dimensão prescrita e da apresentada mostram que os professores possuem pouca noção do currículo prescrito, pois não o conhecem por completo e utilizam o currículo apresentado quando desenvolvem determinados conteúdos matemáticos, complementando-os com outras atividades, como já referimos. Podemos afirmar que esses professores se apropriam do conjunto de atividades propostas nos CAAM, mas o utilizam, às vezes, de forma diferente da intenção dos autores do material curricular, adaptando-o e introduzindo suas próprias estratégias de ensino.

As indicações sobre fragilidades em conteúdos matemáticos propostos para os três primeiros anos da escolaridade, como o funcionamento do sistema de numeração decimal, os procedimentos usados em técnicas operatórias e geometria, apontam para ações de formação mais específicas com esses temas. Fica a percepção de que é preciso melhorar os diferentes tipos de conhecimento necessários à atuação profissional para o ensino de Matemática.

Cabe destacar que as indicações dos professores para retomada de conteúdos matemáticos e para ações de formação mais efetivas que possibilitem maior compreensão desses documentos sugerem alguns cuidados necessários para implementação de propostas curriculares, pois apenas propiciar ações que permitam acesso aos documentos e algumas indicações sobre eles não é suficiente para sua implementação.

\section{Referências}

BRASIL. Constituição da República Federativa do Brasil. Brasília, 1988.

BRASIL. Lei de Diretrizes e Bases da Educação Nacional n. ${ }^{0}$ 9.394, de dezembro de 1996. Brasília, 1996.

BRASIL. Secretaria de Educação Fundamental. Parâmetros Curriculares Nacionais. Brasília: MEC/SEF, 1997.

CAPLAN, S. Using focus group methodology for ergonomic design. Ergonomics, London, v. 33, n. 5, p. 527-533, Apr. 1990. 
CURI, E. Introdução: currículos prescritos, apresentados e avaliados. In: CURI, E.; VECE, J. P. (Org.). Relações espaciais: práticas educativas de professores que ensinam Matemática. 1. ed. Sao Paulo: Terra Cota, 2013. p. 15-20.

GASKELL, G. Individual and Group Interviewing. In: BAUER, M. W.; GASKELL, G. (Ed.). Qualitative Researching with Text, Image and Sound: a practical handbook. London: Sage, 2000. p. 38-56.

SACRISTÁN, J. G. O currículo: os conteúdos do ensino ou uma análise da prática? In: PÉREZ GÓMEZ, A. I.; SACRISTÁN, J. G. Compreender e transformar o ensino. Porto Alegre: Artmed, 1998. p. 119-148.

SACRISTÁN, J. G. O currículo: uma reflexão sobre a prática. Porto Alegre: Artmed, 2000.

SÃO PAULO (Município). Secretaria Municipal de Educação. Diretoria de Orientação Técnica. Orientações curriculares e proposição de expectativas de aprendizagem para o Ensino Fundamental - Ciclo I, $1^{\circ}$ ao $5^{\circ}$ ano. São Paulo: SME/DOT, 2007.

SÃO PAULO (Município). Secretaria Municipal de Educação. Diretoria de Orientação Técnica. Cadernos de Apoio e Aprendizagem: Matemática $-1^{\circ}$ ao $9^{\circ}$ anos. Caderno do Aluno. São Paulo: Fundação Padre Anchieta, 2010.

SHULMAN, L. Renewing the pedagogy of teacher education: the impact of subject-specific conceptions of teaching. In: MONTERO MESA, L.; VAZ JEREMIAS, J. M. (Org.). Las didácticas específicas en la formación del profesorado. Santiago de Compostela: Tórculo Edicións, 1992. p. 53-69. 